\title{
Editorial: If the settler never came
}

\author{
Vincent Backhaus \\ Indigenous Education and Research Centre, \\ James Cook University, QLD \\ Co-Editor
}

Henry Fraser

ARC Centre of Excellence for the

Dynamics of Language, ACT

Co-Editor

Shem Macdonald

La Trobe University, VIC

Co-Editor

If the settler never came and the (Australian) continent developed herself, what kinds of conversations would we consider? Perhaps, we would highlight the fact that the Country and Island landscape did not have an estimated number of languages but significantly more than the speculated 250 (or "over 300", or "hundreds of") Aboriginal and Torres Strait Islander languages across the island and continental landscape. It would be a given continuance that every year across the Country, and not just 2019 declared by the United Nations General assembly, as the year to celebrate the Indigenous languages. Perhaps the ways we define, discuss and distinguish these numerous, living languages would be very different from our current forensic approaches.

We would acknowledge and welcome the understanding language provides to demonstrate how Aboriginal and Torres Strait Islander Peoples continue to maintain relationships through the assumptions of being people of Place, Knowledge and the notion of Science. Country for the continental landscape would reveal a much more detailed patterning of sustainable and meaningful teaching and learning, that would highlight the presence of Aboriginal and Torres Strait Islander Peoples. This notion of sustainable awareness could perhaps have continued to educate the rest of the world on the ways to access mineral and resource wealth without destroying cultural presence across Land and Sea Country. 
Aboriginal and Torres Strait Islander presence would continue to highlight the need to engage with new technologies through language. Perhaps, Aboriginal and Torres Strait Islander Peoples could demonstrate proper ways of inclusivity for visitors from distant lands and how they can be afforded a respect of language, personhood and place from whence they came. We could come to understand that protocols surrounding the sharing of resource and Country is part of understanding the relationships to Country and how she welcomes and takes care of all those who participate in the everyday realties of living on Country and the different ways language guides and shares in such accountabilities.

A Countried perspective of the continent and Island landscape demonstrates how language shares the understanding of place through the embodied and emergent qualities of ways of knowing and being. A Countried perspective rests on the assumptions of the kinds of relational qualities between languages that share in an equity of being visible and heard while ensuring speakers can learn to navigate multiple languages within Place and the everyday realties of Place.

However, the settler did come, they continue to distil and diffuse such assumptions into perspectives of understanding that can maintain Australian presence through language and everyday reality. The notion of Australian language continues to pose a significant challenge for Aboriginal and Torres Strait Islander Peoples to navigate. Country means Australia, language means Standard Australian English and Teaching and Learning about country and the world for Aboriginal and Torres Strait Islander Peoples began on missions and reserves through faith based and state-run educational institutions.

The settler came with cattle and sheep; guns and steel; tea, sugar, flour - and English. Over the past two centuries, power shifted from collectively accountable relationalities facilitated by local interdependent groups each with a language linked to a specific land and history; to a monolithic, hierarchical system, grown from the colonial systems that seeded it. English is the language of the settler, not just as a mode of communication but as a method of maintaining power. Just as this continent was redefined as Australia, Australians were defined as Englishspeaking.

Aboriginal people across the continent began seeing settlers arrive and take control of lands that had been consistently held and managed for tens of thousands of years. Torres Strait Islanders 
also saw visitors pass through, potentially stopping over within their island landscapes and Sea country. As these lands were reshaped by the animals, crops and ways of living the settler brought, the economic advantages of learning and using English increased. Although settlers included Afghans, Chinese, Germans and many other languages and cultures, the British worked to establish English as the language of power. However, Aboriginal people and Torres Strait Islander people did not have full access to the language, nor consistent opportunities to engage with explicit teaching of it, for the significant portion of Australia's history.

As missions and reserves displaced and controlled an increasing proportion of Aboriginal people, and Torres Strait Islanders were blocked and/or restricted from traveling to the continent; English was far more actively taught. Although the experience of Aboriginal and Torres Strait Islander people varied widely in these institutions and elsewhere at different times and places, often languages and cultures were actively suppressed at the same time as English was enforced, establishing the language itself as the oppressor and destroyer. The detail of this history is better told elsewhere, but its legacy is the context and content of this special issue.

The range of language ecologies resulting from a long and complex history of language interaction are described by Hudson and Angelo, along with a clear prescription and advice for our next steps in this field. Further details of experiences with particular contemporary language types and educational responses are described in the other papers of this volume.

At one end of this range, Poetsch describes a place where a First Nations language is still in use - but at risk due to the dominance of English both in educational policy settings and Australian society. At the other, Malcolm, Königsberg and Collard detail the features of "Aboriginal English", a collection of English and English-lexified varieties described as a single dialect defined by the shared cultural schema of its speakers rather than consistent surface linguistic features. Both papers share the experience of educators and language speakers, advising practitioners on what has worked - and what needs to be improved.

Wigglesworth defines and recontextualises translanguaging for Aboriginal and Torres Strait Islander students for whom English is an additional language or dialect. Understanding this 
approach to describing normal and natural language use, she argues, can be an empowering tool in mainstream educators' repertoires, in contrast with past policies and approaches to language instruction.

All four papers share the perspectives and experiences of educators working to balance the historical weight of English with the ongoing power and strength that speaking this language carries.

This isn't the first time TESOL in Context has devoted our pages to Aboriginal and Torres Strait Islander EAL/D learners, and it won't be the last. This special issue marks an important milestone in the thirty year legacy of this journal engaging with Aboriginal and Torres Strait Islander languages.

This journal has consistently contributed to our understanding of Language and Language learning in context. For Aboriginal and Torres Strait Islander languages this includes requiring researchers to self-reflect on the wider accountabilities Country asks of us.

We see this special issue as a call to language researchers to engage deeply with the languages - past, present and future - of Aboriginal and Torres Strait Islander peoples and Countries as we continue to develop and contextualise our understanding of TESOL in this continental and island landscape and seascape. 